\title{
A rare case report of cord entanglement in a post-dated monochorionic monoamniotic twins
}

\author{
Kasturi Donimath, Harsha B*, Rashmi Shalgar
}

Department of Obstetrics \& Gynaecology, Karnataka Institute of Medical sciences, Hubli, Karnataka, India

Received: 07 October 2015

Revised: 25 November 2015

Accepted: 14 December 2015

\section{*Correspondence:}

Dr. Harsha B,

E-mail: b.harsh29@gmail.com

Copyright: $(\odot$ the author(s), publisher and licensee Medip Academy. This is an open-access article distributed under the terms of the Creative Commons Attribution Non-Commercial License, which permits unrestricted non-commercial use, distribution, and reproduction in any medium, provided the original work is properly cited.

\section{ABSTRACT}

Monochorionic Monoamniotic (MCMA) twin gestations have been associated perinatal mortality rates as high as 28 to $47 \%$. Umbilical cord entanglements and knots, twin-to-twin transfusion syndrome, congenital anomalies, prematurity and intertwin locking during labour is responsible for their high perinatal morbidity and mortality. We report here a case of Cord entanglement in a post-dated MCMA twin pregnancy without any complications.

Keywords: Monochorionic, Monoamniotic, Cord entanglements

\section{INTRODUCTION}

Monoamniotic twins have a prevalence of less than 5\% of monozygotic twin gestations and $1 \%$ of all twin pregnancies. ${ }^{1}$ They occur as a result of ovum division beyond eight days after fertilization and are characterized by a single amnion and single yolk sac. There may be two or one (conjoined twins) embryos present.

They are at increased risk of preterm delivery and acute fetal death. Cord entanglement, malformations, twin-totwin transfusion syndrome are responsible for their high perinatal morbidity and mortality. ${ }^{2}$ Literature presents perinatal mortality rates of $28 \%$ and $47 \%$ based mostly on case reports and small series. These high rates are suggested to be specifically due to cord accidents secondary to the entwining of the two umbilical cords and/or knotting and thus leading to occlusion. ${ }^{3}$ Early diagnosis is essential if attempts to reduce the complication rates are to be made. The diagnosis is usually made by ultrasound, with an inability to distinguish a dividing membrane between the foetuses. Colour flow Doppler is useful in the identification of umbilical cord entanglement in monoamniotic twin pregnancies and may provide a method of monitoring fetuses for the evidence of cord compression.

In this study, we present a case of post-dated monoamniotic twin pregnancy with cord entanglement.

\section{CASE REPORT}

A 20-year-old primigravida came to our hospital as an unbooked case at 40 weeks 4days gestation with complaints of pain abdomen in latent labour. On examination, she had no signs of pallor, icterus, cyanosis, clubbing, lymphadenopathy or edema. She was normotensive.

Her sonography report at 30 weeks showed twin gestations in single amniotic cavity (amniotic membrane could not be visualized) indicating a monochorionic monoamniotic twin gestation, without any congenital anomalies. 
A repeat scan was done which showed both twins in cephalic presentation in a single amniotic cavity, with $>2$ $\mathrm{kg}$ of estimated fetal weight with good cardiac activity and adequate liquor. Keeping in mind the risks and adverse events, a decision for caesarean section was taken.

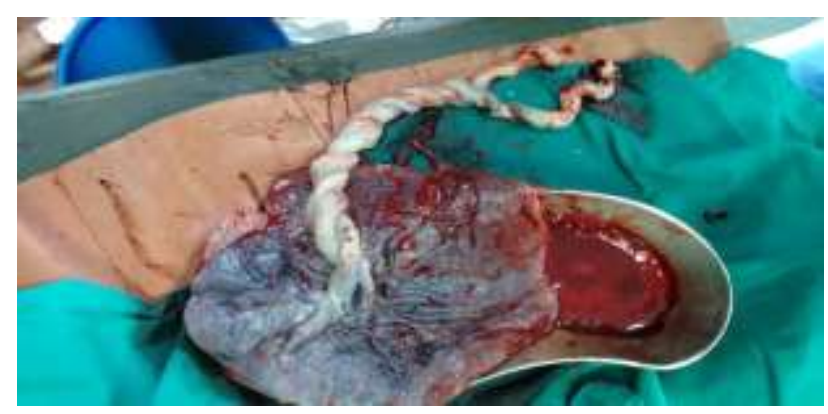

Figure 1: Cord entanglement.

Intra-operatively, the single amniotic sac was ruptured and clear liquor drained. Both babies were extracted by Vertex and both cried immediately after birth, weighing 2.2 and $2.3 \mathrm{kgs}$. The cords were entangled around each other without any evidence of compression.

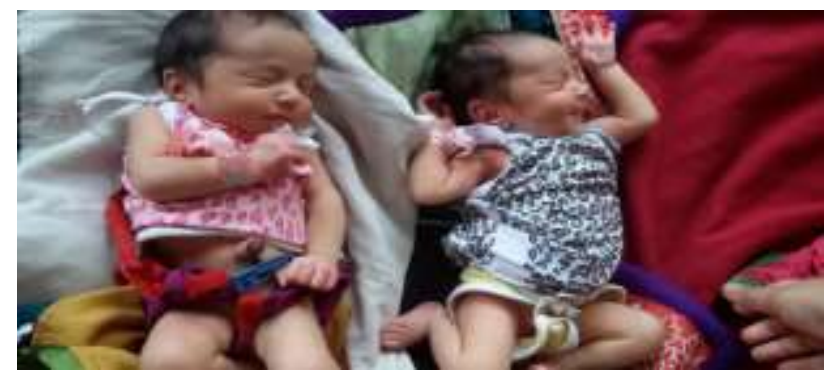

Figure 1: Babies post-caesarean.

\section{DISCUSSION}

Monochorionic monoamniotic twin gestations derive from a single blastocyst in which the zygotic division takes place for more than 8 days after fertilization. ${ }^{4}$ In these pregnancies, the fetuses are at high risk because of shared vascular areas as well as cord accidents and birth trauma. Vascular anastomoses generally occur between fetuses and monochorionic placentas and can cause twinto-twin transfusion or twin reversed arterial perfusion, thus developing the risk of intrauterine fetal demise or prematurity as a cause of preterm delivery. Cord entanglements are the main risk of these pregnancies, developing in very early gestational ages and a crucial problem in later weeks.

Twin-to-twin transfusion syndrome may also occur in these pregnancies, due to the unbalanced unidirectional flow along the arteriovenous anastomoses, causing anemia, growth restriction and Oligohydramnios. ${ }^{6}$ Fetal survival rate is less than $10 \%$ if conservative approach is sought.
Twin reversed arterial perfusion (TRAP) sequence can also occur, in which the normal (pump) twin donates blood to the other twin with absent cardiac structure (acardiac). The incidence is 1 in 350000 pregnancies and $1 \%$ of Monochorionic pregnancies. This results in the reversal of flow in the umbilical cord vessel of the recipient twin, leading to better development of the pelvis and lower extremities and atrophy of heart and nondevelopment of head and upper limbs. ${ }^{6}$

Clinical management of these pregnancies remains to be clarified. Limited data are available on the timing and mode of delivery for twins. General thoughts have been focused upon the termination of pregnancy at 32-34 weeks or after lung maturation for monoamniotic twins. ${ }^{7}$

\section{CONCLUSION}

Monoamniotic monochorionic twin pregnancies have an increased risk of cord entanglement, twin-to-twin transfusion syndrome, prematurity and congenital malformations. The research based on determinations of chorionicity and amnionicity via first trimester sonography would be helpful for planning fetal surveillance and neonatal follow-up.

\section{Funding: No funding sources \\ Conflict of interest: None declared \\ Ethical approval: Not required}

\section{REFERENCES}

1. Cordero L, Franco A, Joy SD. Monochorionic Monoamniotic twins: neonatal outcome. J Perinatol. 2006;26:170-5.

2. Sherer DM, Sokolovsli M, Haratz-Rubinstein N. Diagnosis of umbilical cord entanglement of monoamniotic twins by first trimester color Doppler imaging. J Ultrasound Med. 2002;21:1307-9.

3. Dickinson JE. Monoamniotic twin pregnancy: a review of contemporary practice. Aust NZ J Obstet Gynaecol. 2005;45:474-8.

4. Benirschke K. The biology of twinning process: how placentation influences outcome. Semin Perinatol. 1995; 19:342-50.

5. Carr SR, Aranson MP, Coustan DR. Survival rates of monoamniotic twins do not decrease after 30 weeks gestation. Am J Obstet Gynecol. 1993;168:601-4.

6. Renu Misra. Ian Donald's Practical Obstetric Problems; $7^{\text {th }}$ ed:353-75.

7. Lee YM. Delivery of twins. Semin Perinatol. 2012; 36(3):195-200.

Cite this article as: Donimath $\mathrm{K}$, Harsha B, Shalgar $\mathrm{R}$. A rare case report of cord entanglement in a postdated monochorionic monoamniotic twins. Int J Reprod Contracept Obstet Gynecol 2016;5:230-1. 